\title{
The Effect of Breakfast Education Program for Parents on Academic Achievement of Primary School Children
}

\author{
Mariam Kawafha ${ }^{1}$ \\ ${ }^{1}$ Associate Professor, Irbid National University, Irbid, Jordan \\ Correspondence: Mariam Kawafha, Associate Professor, Irbid National University, Irbid, Jordan. E-mail: \\ mariamsltn204@gmail.com
}

Received: February 1, 2018 Accepted: March 5, 2018 Online Published: March 13, 2018

doi:10.5539/gjhs.v10n4p77 URL: https://doi.org/10.5539/gjhs.v10n4p77

\begin{abstract}
The study aims to explore whether the breakfast education intervention offered to parents, leads to improvement in students' breakfast and their academic achievements. Data was collected regarding the demographics of the children and their daily breakfast consumption through questionnaire. 250 Jordanian parents of children acquiring education from public-primary schools were recruited. Statistically significant differences were observed between the experimental and control groups ( $\mathrm{p}$-value $=0.001<0.05$ ), the results supported the experimental group regarding academic achievement scores. Targeting parents for health education about breakfast is crucial for activating the parental concerns towards breakfast, because of its importance and effects on children academic attainments.
\end{abstract}

Keywords: breakfast, academic achievement, primary school children, breakfast education program, parents

\section{Introduction}

Traditionally, breakfast is an essential meal in a person's daily life. Studies indicated that various students take advantage from consuming breakfast in two ways. Firstly, the dietary health of a student is affected positively by consuming breakfast. Secondly, significant evidences indicated positive educational effects due to consumption of breakfast (Kawafha, 2013; Glewwe et al., 2001). The purpose of this study was to examine the effect of Breakfast Education Program for parents on the academic achievement of their children in public/primary schools of Jordan.

The significance of regularly taken meals especially breakfast regularity and consumption with regular dietary energy are important for psychological and physical development. Numerous studies have examined that the breakfast consumption and academic performance of the adolescents and children are directly associated factors in routine life (Edward \& Evers, 2001; Abalkhail \& Shawky, 2002). It has been investigated that there is a direct and positive influence of breakfast on several different academic achievements and related activities. Better grades in mathematics and regular attendance have been observed among the students with low nutritional risk as compared to higher nutrition risk based on the breakfast programs in schools (Kleinman et al., 2002).

Taras (2005) argued that children are expected to have low lateness rates, when there is a breakfast program at school. Students can perform well and concentrate more on the academic classes, when have proper breakfast before going to school (Edward \& Evers, 2001). Low cognitive abilities have been observed in the students, who skip breakfast and this is the reason of poor health and nutrition deficits among children. Some studies further suggested that breakfast intake provides high levels of nutrient intake that augments student's cognitive capabilities (Woodhouse \& Mark, 2012) and improves educational performance, (Florence et al., 2008; Gleason \& Suitor, 2003; Kleinman et al., 2002) Children, who consume breakfast regularly are less probable to be either obese or overweight (Satoh et al., 2007). Numerous negative consequences have been linked with skipping breakfast, including reduced educational performance (Adolphus et al., 2013), behavioral problems like fighting, stealing, not listening to the supervisor (Murphy et al., 1998), limited ability to concentrate, impaired immune system (Kraak \& Story, 2015), poor diet, high BMI (body mass index), along with adversely affecting academic performance and children's behavior (Castelli et al., 2007). The most common justifications for not eating breakfast demonstrated in the past evidences included; lack of time, increased workload, prolonged sleep, lack of appetite, and not being capable of consuming food early in the morning (Murphy et al., 1998). Previous research conducted by Kawafha (2013) estimated that approximately one-quarter of school children regularly skip breakfast in Northern Jordan. It has been highly recommended to begin the day with a healthy breakfast, which contains all the important nutrients (Chitra \& Reddy, 2007). 
In the other side; there is absence of providing adequate nutritional knowledge in schools due to lack of nurse's role in Jordanian schools. This refers that there is a requirement for increased nursing role to promote the breakfast consumption among the school children. The course should be reviewed to educate school community including parents. This education should not only be conducted to promote training about nutrition, but enhancing the levels of clinical nutrition as a part of clinical health application and nursing care services.

Within these evidences, it is essential to focus on parents' role to take the breakfast meal of their children attentively. It can be done by conducting breakfast education program for parents in public/primary schools of Jordan. Therefore, it is important to examine the effect of Breakfast Education Program for parents on the academic achievement of their children.

Eating breakfast has a positive impact on health, diet, and cognition (Nicklas et al., 2000). It was evaluated that children, who eat breakfast, have better overall diet. Rate of school going children, who skip breakfast ranges between 5\% and 31\% (Nicklas et al., 1995). In addition, it has been reported that skipping breakfast or consuming inadequate breakfast ensures dietary inadequacies that cannot be compensated with later meals (Hanes, Vermeersch \& Gale, 1984). When breakfast is available in schools; it ensures low-income children that they will be getting breakfast to eat (Devaney \& Stuart, 1998). Moreover, children who participate in breakfast programs, showed better overall diet quality than those, who skip breakfast or those who eat it at home. However, it has been reported that children, who suffer from hunger, suffer from hyperactivity and impaired mental function (Murphy et al., 1998). Whereas, aggression and anxiety are normally found in association with hunger (Kleinman et al., 1998). While considering U.S, one-quarter of individuals skip breakfast and these people have $16 \%$ of total caloric intake. In addition, it was found that breakfast plays a vital role in omitting obesity. It controls the additional intake of calories as well as ensures physical activity.

Inspite of knowing that 'breakfast is the most important meal of the day', it has been reported by the Austrailian Bureau of Statistics (2011) that one in every 6 children in Austrailia skip breakfast regularly. What children and most importantly their parents fail to understand is that skipping breakfast can lead to various health problems for children as well contribute to poor academic performance. Therefore, it is the responsibility to ensure that children eat nutritious breakfast daily as parents and teachers.

The study was conducted in accordance to find out how many parents are actually aware about breakfast pograms. It was taken into consideration that parents and caregivers are responsible to establish a healthy model for their children by helping them or inspiring them to eat healthy breakfast. Therefore, it was of utmost importance to find out how many parents take it for granted that their children are skipping morning breakfast and welcoming many health related issues. In addition, it was done to let them know that breakfast not only enhances children activities, but also improve their nutritional status. Therefore, the study aims to explore whether the breakfast education intervention, offered to parents, leads to improvement in students' breakfast and their academic achievements. Following research questions have been developed:

1) What are effects of breakfast education program on parents?

2) What is the impact of such programs on academic achievement of primary school children?

\section{Methods}

\subsection{Design}

An experimental (Pretest-Posttest) randomized controlled trial was used to examine whether the breakfast education programs for parents lead to improvement in students' breakfast and their academic achievements or not.

\subsection{Study Sample and Population}

Jordanian parents of the students, studying in public/primary schools of "North of Jordan" were recruited in the study as target population. The accessible population included parents of children selected from public/primary schools of all governorates in the North of Jordan. G*Power software introduced by Faul et al. (2007), was used to calculate the sample size. For this study, the medium effect size was also required, which was calculated to be 0.5 . The size of sample was examined for independent t-test by means of power level (0.80). Moreover, $\alpha=0.05$ was used as a conventional two tailed significance criterion. An addition of 50 parents was allowed to the final size of sample to overcome the rate of participant attrition. 250 participants were included in the study, and the participants were equally and randomly divided into experimental and control groups. All parents/caregivers reported that not even a single participant received a workshop or an educational session about breakfast. The participants acknowledged that their children did not eat breakfast regularly, and their children were free from chronic diseases. 


\subsection{Intervention Breakfast Education Program}

The educational program of breakfast was presented by the interventionist for parents (recipient) of primary school children aged 06-12 years old. The researcher, who conducted the intervention has a philosophy degree in nursing. The program contents covered different topics including: general breakfast information, importance of breakfast, imperative reasons about child not accepting to eat breakfast, limited time to cook breakfast, and tips to encourage a child to eat breakfast. This information was limited to dietary interventions along with their benefits. The breakfast educational program was evaluated by 2 nutritionists and pediatric specialist to examine the information sufficiency and content for the study participants.

\subsection{Measures}

This section consists of two segments of tools; the first segment was demographic questionnaire that was developed by researcher; included child's age, class, and presence of child's chronic disease, child's breakfast-eating behavior, parent's education, monthly income, and number of family members. This was finished by caregivers or parents of a child. The second segment comprises of the child's educational achievement, and assessments as per the values derived from CPE (Child's Jordan Certificate of Primary Education). The raw score of CPE included grades sheet of student in all subjects. The schools always possessed one copy of the certificate. The records of child for the last academic semester were also retrieved.

\subsection{Procedure of Data Collection}

A catalog of public-primary schools situated in the vicinity of North of Jordan, comprised of children (aged 6 to 12 years), which was acquired from the educational ministry by using a technique of 'cluster random sampling'. This method of sampling was undertaken in a multistage aspect. The 5 stages clusters random sampling was utilized in the study as follows. First stage; selection of governorate by listing all the governorate in the slips of paper and the selection of one governorate. Stage two; selection of 2 schools from the selected governorate, by listing all primary schools' children on a slip of paper. In the third stage; the researcher listed 2 schools in the slips of paper to select the intervention group. The fourth stage; selection of classrooms; all classrooms were written on slips of paper and the researcher went to the selected classrooms according to the order of random selections. The fifth and final stage; selection of $10 \%$ students from each class; the researcher written all students' number to draw the sample. The researcher delivered the demographic questionnaire to every selected participant for their parents that was kept in an envelope with thorough directions. The researcher collected questionnaire from children on the second day.

Collected data related to the academic performance of children was obtained through the CPE scores, which were also banded. As per the percentages: 90-100 was excellent, 80-89 was considered to be very good; $70-79$ was considered to be good; 60-69 was poor, 50-59 was very poor and less than 50 depicted failure.

New mean scores of children were measured to compare them with the mean scores before and after intervention, within and between groups in relation to breakfast consumption.

After one week, parents in the experimental group $(n=125)$ were given a 'PowerPoint presentation' followed by a lecture discussion. The duration of the lecture consumed an hour for 3 days. In the second and third sessions, the experimental group dropped out to become 102 participants due to lack of time. During this time, control group $(\mathrm{n}=125)$ was not given any interventions. On the 3 months (at the end of the first semester) after the intervention, the post-test about breakfast was performed for both intervention and control groups. During the three-month after intervention the researcher-maintained follow-up, the researcher used electronic reminder to experimental group via WhatsApp, every 2-4 weeks after intervention (Figure 1). 


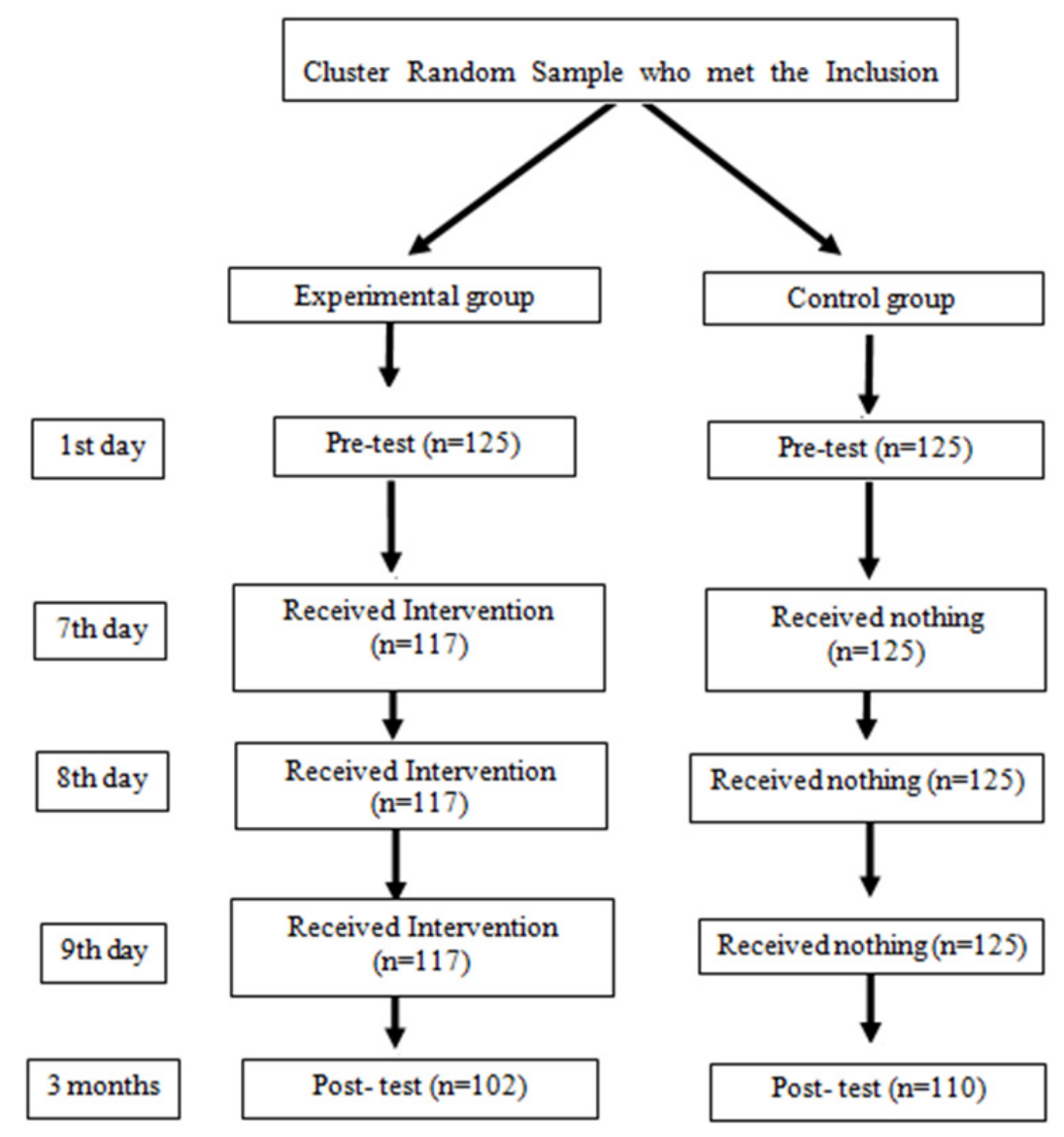

Figure 1. Procedure of Data Collection

\subsection{Ethical Considerations}

Research Ethical committee is mainly responsible to review studies regarding participants and ensures that they are in compliance with the ethical guidelines. Committee is solely responsible and authorized to reject, approve or stop studies, if they feel like. The investigation was permitted by the end of Research Ethical Committee at Education Ministry. A written consent was also received from parents as soon as they agreed to take part in the study. From the beginning; it was ensured that parents are informed about the data that would be taken from them. Anonymity and confidentiality of the obtained information were also guaranteed and was maintained by coded numbers. Coded numbers ensure tracking of respondents over multiple data collection points anonymously. As well as, it ensures the confidentiality of participant's data as well. Whereas, files that contain electronic data are pass-word protected as well as the data is encrypted. Furthermore, data obtained from research are stored separately ensuring no unauthorized access.

\section{Results}

Participants $(n=250)$ recruited from randomly selected schools were randomly assigned either to control or experimental group. Hence, there were 125 participants in each group at the baseline. The mean age of parents was $33.40(\mathrm{SD}=4.50)$, with a mean monthly income of 510 Jordan dinars $(\mathrm{SD}=180)$. Regarding the parental education, the results revealed that 129 (51.6\%) had a bachelor's degree, 70 (28\%) had a diploma and 51 (20.4\%) had secondary education or less (Table 1). Caregivers of children; mothers showed the highest percentage 242 (96.8\%) followed by the grandmothers $7(2.8 \%)$. Whereas, the percentage of house maid was $1(0.4 \%)$. The characteristics of school-children are represented in the Table 1. 
Table 1. Demographics information of parents/caregiver of schoolchildren aged (6-12) years $(\mathrm{n}=250)$

\begin{tabular}{ll}
\hline Demographics & $\mathrm{M}(\mathrm{SD})$ \\
\hline Variables & $\begin{array}{l}33.40(\mathrm{~S} . \mathrm{D}=4.50) \\
510(\mathrm{~S} . \mathrm{D}=180)\end{array}$ \\
\hline Age & $\mathrm{n}(\%)$ \\
\hline Monthly Income & \\
\hline Parent Education & $129(51.6 \%)$ \\
Parent's with bachelor degree & $70(28 \%)$ \\
Parent's with diploma & $51(20.4 \%)$ \\
Secondary Education or less & $242(96.8 \%)$ \\
\hline Caregivers of Children & $7(2.8 \%)$ \\
Mothers & $1(0.4 \%)$ \\
Grandmothers & \\
House maid &
\end{tabular}

\subsection{Pre-Intervention Test}

Before the intervention at baseline the data was measured by independent sample t-test; to assess the level of homogeneity between the study participants (parents/caregivers) in terms of age, and income. Independent sample t-test demonstrated no statistically significant differences between the groups in terms of monthly income ( $\mathrm{p}$-value $=0.18$ ), and age ( $\mathrm{p}$-value $=0.21)$. Indicating that the 2 groups are homogenous. Additionally, Mann Whitney U Test was used in pre-intervention to assess the level of education of parents/caregivers between the control and experimental groups. This test indicated that no significant difference existed between the control and experimental groups in pre-intervention with regards to the level of education $(\mathrm{Z}=-4.3, \mathrm{P}=.22)$. At baseline, out of 250 participants $212(90.6 \%)$ ultimately accomplished the study. Of these, $102(48.1 \%)$ were found in experimental group and 110 (51.9\%) were in control groups.

An independent sample t-test also was conducted at pre-interventional study to assess children ages and academic achievement scores between children in experimental and control group. The result of this test has indicated that the difference between children of participants in experimental $(M=61.49, S D=8.69)$ and control $(M=62.89$, $\mathrm{SD}=6.34$ ) groups was not statistically significant regarding academic achievement scores with the $\mathrm{p}$-value of 0.92 , similarly, observed children ages with insignificant difference as the ( $p$-value $=0.36$ ). Therefore, the 2 groups were considered to be alike (Table 2).

\subsection{Post Intervention Test}

In the post-intervention; as it is presented in table 2; an independent t-test demonstrated that there was a statistically significant difference $(\mathrm{p}$-value $=0.001<0.05)$, between children whose parents were in the experimental group $(\mathrm{M}=78.91, \mathrm{SD}=7.23)$, and in the control group $(\mathrm{M}=66.24, \mathrm{SD}=11.94)$ regarding academic achievement scores.

The "paired t-test" suggested that statistically significant difference existed between the mean academic achievement scores of children before $(\mathrm{M}=61.49, \mathrm{SD}=8.69)$ and at three months $(\mathrm{M}=78.91, \mathrm{SD}=7.23), \mathrm{P}<0.001$, after the application of breakfast education intervention for their parents. In addition, the results suggested an improvement in the mean score for all people, after applying the program. This directed to implement improvement in all knowledge fields, including English language, Arabic language, Math, Science and History. There was no significant difference found in the mean academic achievement score of children whose parents were not exposed to the intervention $(\mathrm{M}=66.24, \mathrm{SD}=11.94), \mathrm{P}<0.59, \mathrm{t}(109)=.24)$. Table 2 depicted the Mean Difference of their children in the Pre-Post Test between the Experimental $(\mathrm{N}=125)$ and Control Groups $(\mathrm{N}=125)$. 
Table 2. Independent $\mathrm{t}$-test of the Pre-Posttest between the Experimental $(\mathrm{N}=125)$ and Control Groups $(\mathrm{N}=125)$

\begin{tabular}{|c|c|c|c|c|c|c|}
\hline \multirow[b]{2}{*}{ Variable } & \multicolumn{2}{|c|}{ Pre-Test Groups } & \multirow[b]{2}{*}{$p$ value } & \multicolumn{2}{|c|}{ Post-Test Groups } & \multirow[b]{2}{*}{$P$ value } \\
\hline & $\begin{array}{l}\text { Experimental } \\
(n=125) \\
M(S D)\end{array}$ & $\begin{array}{l}\text { Control } \\
(n=125) \\
M(S D)\end{array}$ & & $\begin{array}{l}\text { Experimental } \\
(n=102)\end{array}$ & $\begin{array}{l}\text { Control } \\
(n=110)\end{array}$ & \\
\hline Parents Age (years) & $33.80(6.50)$ & $34.0(1.69)$ & .21 & - & - & - \\
\hline Children Age (years) & $9.36(1.78)$ & $9.41(1.83)$ & .36 & & & \\
\hline Monthly Income (Jordanian Dinar) & $480(170.31)$ & $540(177)$ & .18 & - & - & - \\
\hline Academic achievement & $61.49(8.69)$ & $62.9(6.34)$ & .92 & $78.91(7.23)$ & $66.2(11.9)$ & .001 \\
\hline
\end{tabular}

Level $\left({ }^{*} p \leq .05\right.$ two-tailed).

\section{Discussion}

This study used an experimental (Pretest-posttest) randomized controlled trial to examine whether the health education intervention about breakfast for parents leads to improvement in students' breakfast intake and their academic achievements or not. The present study has reported that having breakfast regularly can be a vital aspect in improving students' learning skills. According to Scope and Standards of School Nursing Practice (NASC) and American Nurses Association, (2005), these outcomes are interesting as the health teaching serves as expectation of the school nurse. Especially, Jordan does not activate the role of school nurse, which may play a significant part in motivating the decision makers and stakeholders for stimulating the role of school nurse in Jordan. The activated role for school nurse can assist school children to live longer, productive, and healthier lives.

Alaimo et al., (2001) argued that there are several students, who did not take breakfast in the morning regularly. Children of ages between six to eleven years were more probable to repeat a grade because of lower scores, especially in mathematics and have psychological difficulties of being with other children. Gibson (2003) found that Vitamin D are 20-60 percent higher in children, who consume their breakfast regularly as compared with the students who skip breakfast. The considerable impact of breakfast education for parents on their children's academic achievement and breakfast intake is attributed to numerous factors. These factors include proper application of techniques, frankness with parents and loyalty to the program. In addition; making use of multi-teaching resources for instance, educational video, data show, and pamphlet. Teaching methods in addition to support the importance of breakfast for children cognitive and physical growth; used in this study assisted in improving the parents' understanding about importance of breakfast.

The main finding demonstrated statistically significant difference at $\alpha=0.001$ intake of breakfast among children assigned to the control and experimental group. After the three-month follow-up, $90 \%$ of the parents $(n=92)$ in experimental group reported that their children had taken regular breakfast. However, only $16.4 \%$ of the parents $(\mathrm{n}=18)$ indicated that their children had taken regular breakfast in control group. The posttest favors the experimental group as the parents in this group were exposed to the educational program about breakfast. The finding of this study is consistent with previous studies, which have conducted a randomized control trial of a community-based nutrition education program (ALBashtawy, 2015; Ni et al., 2009). This difference indicated that increased parental knowledge and understanding of the importance of breakfast can have a major impact on the nutritional health status of children and their academic achievement. Children who regularly skip breakfast are more frequently ill because they suffer from problems related to hunger, such as dizziness, lethargy and stomachaches. Children who skip breakfast are more probable to be less active physically and it effects their cognitive, behavior and school performance (Adolphus et al., 2013).

The findings of this study also indicated a strong need to educate parents of school children not only about the breakfast meal, which offers at least one third of daily food requirement but also for other health problems. Several studies have found that appropriate educational programs often help to improve knowledge of parents and improves child educational attainments (Kawafheh et al., 2014;Al-Omiri et al., 2006).

Based on these findings, a solid strategy needs to be formed to improve the life quality of child regarding her/his academic achievements. One of the studies has suggested the recommendations for the breakfast consumptions, high in whole grains and low in sugars added, might be beneficial for the academic performance in the schools for children (Rampersaud et al., 2005).

\section{Conclusion}

This study has supported the strength of the health intervention to educate parents about the breakfast importance 
and its consequent outcomes on children's academic achievement. The strengths of this study include effective blinding procedure and wider sample size. Effective blinding procedure indicated that the participants were randomly placed into groups without having any prior knowledge about their assignment into groups. Breakfast education programs should be implemented across Jordan, targeting parents to enhance school children's health status and an academic achievement. The learning development of the children can be improved by activating parental concerns. However, the implementation of breakfast educational programs is of equal importance across the globe. Especially, it is a known fact that not many parents are aware about it. Therefore, an awareness should be given to parents about the significant of breakfast for better quality of life.

\section{Recommendation}

It is of utmost importance that every child gets healthy nutritious breakfast. Therefore, an awareness level is required for the parents about its significant. For this purpose, the study suggests that awareness programs should be held for parents to increase the rates of breakfast consumption. One of the most common reasons why children skip breakfast is related to their insistence.

\section{Acknowledgement}

The author is very thankful to all the associated personnel in any reference that contributed in/for the purpose of this research.

\section{Conflict of Interest}

The research has no conflict of interest and is not funded through any source.

\section{References}

Abalkhail, B., \& Shawky, S., (2002). Prevalence of daily breakfast intake, iron deficiency anaemia and awareness of being anaemic among Saudi school students. International journal of food sciences and nutrition, 53, 519-528. https://doi.org/10.1080/09637480220164370

Adolphus, K., Lawton, C. L., \& Dye, L., (2013). The effects of breakfast on behaviour and academic performance in children and adolescents. Frontiers in human neuroscience, 7. https://doi.org/10.3389/fnhum.2013.00425

Alaimo, K., Olson, C. M., \& Frongillo, E. A. (2001). Food insufficiency and American school-aged children's cognitive, academic, and psychosocial development. Pediatrics, 108(1), 44-53.

ALBashtawy, M., (2015). Exploring the reasons why school students eat or skip breakfast: Mohammed ALBashtawy describes a study to determine whether sociodemographic factors affect the likelihood that children will consume or miss breakfast, and to examine how the chosen habitual behaviour correlates with nutritional status. Nursing children and young people, 27, 16-22. https://doi.org/10.7748/ncyp.27.6.16.e622

Al-Omiri, M. K., Al-Wahadni, A. M., \& Saeed, K. N., (2006). Oral health attitudes, knowledge, and behavior among school children in North Jordan. Journal of dental education, 70, 179-187.

Australian Bureau of Statistics. (2011). Statistics. Retrieved from http://www.abs.gov.au/

Castelli, D. M., Hillman, C. H., Buck, S. M., \& Erwin, H. E., (2007). Physical fitness and academic achievement in third-and fifth-grade students. Journal of Sport and Exercise Psychology, 29, $239-252$. https://doi.org/10.1123/jsep.29.2.239

Chitra, U., \& Reddy, C. R., (2007). The role of breakfast in nutrient intake of urban schoolchildren. Public health nutrition, 10, 55-58. https://doi.org/10.1017/S1368980007219640

Devaney, B., \& Stuart, E. (1998). Eating breakfast: Effects of the school breakfast program.

Edward, H. G., \& Evers, S., (2001). Benefits and barriers associate dwith participation in food programs in three low-income Ontario communities. Canadian journal of dietetic practice and research, 62, 76.

Faul, F., Erdfelder, E., Lang, A. G., \& Buchner, A., (2007). G* Power 3: A flexible statistical power analysis program for the social, behavioral, and biomedical sciences. Behavior research methods, 39, 175-191. https://doi.org/10.3758/BF03193146

Florence, M. D., Asbridge, M., \& Veugelers, P. J. (2008). Diet quality and academic performance. Journal of school health, 78, 209-215. https://doi.org/10.1111/j.1746-1561.2008.00288.x

Gibson, S., (2003). Micronutrient intakes, micronutrient status and lipid profiles among young people consuming different amounts of breakfast cereals: further analysis of data from the National Diet and Nutrition Survey of Young People aged 4 to 18 years. Public Health Nutrition, 6, 815-820. https://doi.org/10.1079/PHN2003493

Gleason, P.M. and Suitor, C.W., (2003). Eating at school: How the National School Lunch Program affects children's diets. American Journal of Agricultural Economics, 85, 1047-1061. 
https://doi.org/10.1111/1467-8276.00507

Glewwe, P., Jacoby, H. G., and King, E. M. (2001). Early childhood nutrition and academic achievement: A $\begin{array}{lllll}\text { longitudinal analysis. Journal of Public Economics, } & 8, & \text { 345-368. }\end{array}$ https://doi.org/10.1016/S0047-2727(00)00118-3

Hanes, S., Vermeersch, J., \& Gale, S. (1984). The National Evaluation of School Nutrition Programs: program impact on dietary intake. The American Journal of Clinical Nutrition, 40(2), 390-413. https://doi.org/10.1093/ajen/40.2.390

Kawafha, M. M. (2013). Impact of skipping breakfast on various educational and overall academic achievements of primary school children in northern of Jordan. Australian Journal of Basic and Applied Sciences, 7, 155-160.

Kawafheh, M.M., Hamdan, F.R., Abozeid, S.E.S. and Nawafleh, H., (2014). The effect of health education programs for parents about breakfast on students' breakfast and their academic achievement in the north of Jordan. International Journal of Advanced Nursing Studies, 3, 84. https://doi.org/10.14419/ijans.v3i2.2482

Kleinman, R. E., Hall, S., Green, H., Korzec-Ramirez, D., Patton, K., Pagano, M. E., \& Murphy, J. M. (2002). Diet, breakfast, and academic performance in children. Annals of Nutrition and Metabolism, 46, 24-30. https://doi.org/10.1159/000066399

Kraak, V. I., \& Story, M. (2015). Influence of food companies' brand mascots and entertainment companies' cartoon media characters on children's diet and health: a systematic review and research needs. Obesity reviews, 16, 107-126. https://doi.org/10.1111/obr.12237

McDonnell, E., Probart, C., Weirich, J. E., Hartman, T., \& Birkenshaw, P. (2004). School breakfast programs: perceptions and barriers. Journal of Child Nutrition \& Management, 2. 57-66

Murphy, J. M., Pagano, M. E., Nachmani, J., Sperling, P., Kane, S., \& Kleinman, R. E. (1998). The relationship of school breakfast to psychosocial and academic functioning: cross-sectional and longitudinal observations in an inner-city school sample. Archives of Pediatrics \& Adolescent Medicine, 152(9), 899-907. https://doi.org/10.1001/archpedi.152.9.899

Murphy, J. M., Pagano, M. E., Nachmani, J., Sperling, P., Kane, S., \& Kleinman, R. E. (1998). The relationship of school breakfast to psychosocial and academic functioning: cross-sectional and longitudinal observations in an inner-city school sample. Archives of Pediatrics \& Adolescent Medicine, 152, 899-907. https://doi.org/10.1001/archpedi.152.9.899

National Association of School Nurses (NASN) \& American Nurses Association (ANA). (2005). School nursing: Scope and standards of practice. Washington, DC: Author.).

Ni, M. C., Turley, M., Gorton, D., Jiang, Y., Michie, J., Maddison, R., \& Hattie, J. (2009). Effects of a free school breakfast programme on school attendance, achievement, psychosocial function, and nutrition: A stepped wedge cluster randomised trial. BMC public health, 10, 738-738. https://doi.org/10.1186/1471-2458-10-738

Rampersaud, G. C., Pereira, M. A., Girard, B. L., Adams, J., \& Metzl, J. D., (2005). Breakfast habits, nutritional status, body weight, and academic performance in children and adolescents. Journal of the American Dietetic Association, 105(5), pp.743-760. https://doi.org/10.1016/j.jada.2005.02.007

Satoh, A., Menzawa, K., Lee, S., Hatakeyama, A., \& Sasaki, H. (2007). Dietary guidance for obese children and their families using a model nutritional balance chart. Japan Journal of Nursing Science, 4, 95-102. https://doi.org/10.1186/1471-2458-10-738

Taras, H. (2005). Nutrition and student performance at school. Journal of school health, 75, 199-213. https://doi.org/10.1111/j.1746-1561.2005.00025.x

Woodhouse, A., \& Mark, A. (2012). The relationship of food and academic performance: A preliminary examination of the factors of nutritional neuroscience, malnutrition, and diet adequacy. Christian Perspectives in Education, 5, 1.

\section{Copyrights}

Copyright for this article is retained by the author(s), with first publication rights granted to the journal.

This is an open-access article distributed under the terms and conditions of the Creative Commons Attribution license (http://creativecommons.org/licenses/by/4.0/). 